\title{
Controlled Cytotoxicity of Plasma Treated Water Formulated By Open-air Hybrid Mode Discharge
}

\author{
Peng Lu \\ Technological University Dublin \\ Daniela Boehm \\ Technological University Dublin, daniela.boehm@tudublin.ie \\ Paula Bourke \\ Technological University Dublin, paula.bourke@tudublin.ie
}

See next page for additional authors

Follow this and additional works at: https://arrow.tudublin.ie/scschbioart

Part of the Biology Commons

\section{Recommended Citation}

Lu, P., Boehm, D., Cullen, P. \& Bourke, P. (2017). Controlled cytotoxicity of plasma treated water formulated by open-air hybrid mode discharge.Applied Physics Letters110, 264102. doi:10.1063/1.4990525

This Article is brought to you for free and open access by the School of Biological Sciences at ARROW@TU Dublin. It has been accepted for inclusion in Articles by an authorized administrator of ARROW@TU Dublin. For more information, please contact arrow.admin@tudublin.ie, aisling.coyne@tudublin.ie,gerard.connolly@tudublin.ie.

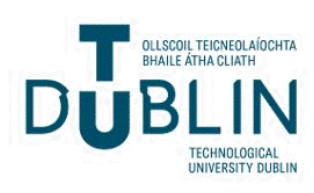




\section{Authors}

Peng Lu, Daniela Boehm, Paula Bourke, and Patrick Cullen 
Article type: Full Paper

\title{
Title $^{\mathrm{a}}$ : Achieving Reactive Species Specificity within Plasma Activated Water through Selective Generation using Air Spark and Glow Discharges
}

Peng LU ${ }^{1,2}$, Daniela Boehm ${ }^{1}$, Paula Bourke ${ }^{1 *}$, P J Cullen $^{1,3}$,

1. Plasma Research Group, College of Science and Health, Dublin Institute of Technology, Dublin 1, Ireland

2. School of Aeronautical Automation, Civil Aviation University of China, Tianjin 300300, China

3. School of Chemical Engineering, University of New South Wales, Sydney, Australia. E-mail: ((paula.bourke@dit.ie))

\begin{abstract}
Plasma activated liquids (PAL) attract increasing interest with demonstrated biological effects. Plasma exposure in air produces stable aqueous reactive species which can serve as chemical diagnostics of PAL systems. Here, we tailor aqueous reactive species inside plasma activated water (PAW) through treating water with AC air spark and glow discharges in contact with water. Chemical probing demonstrated species specificity between two types of PAW. Spark discharge PAW contains $\mathrm{H}_{2} \mathrm{O}_{2}$ and $\mathrm{NO}_{3}^{-}$, while $\mathrm{NO}_{2}^{-}$and $\mathrm{NO}_{3}^{-}$are generated in glow discharge PAW. Species formation in different PAWs have been discussed in terms of discharge mechanisms and liquid phase chemistry process. Species specificity can provide richer parametric spaces for producing PALs with controlled impact and dosage achievable by combining discharge modes or mixing different PALs.
\end{abstract}

\section{Introduction}

${ }^{a}(($ Other reference to the authors can also appear here, such as Author-One and Author-Two contributed equally to this work.)) 
It has been comprehensively demonstrated that atmospheric cold plasma (non-thermal equilibrium plasma) has strong antimicrobial effects using direct plasma treatment of both dry and wet targets ${ }^{[1-3]}$. Apart from direct plasma exposure of materials, plasma activated liquids (PALs) or plasma processed liquids (PPLs) have demonstrated efficacy ${ }^{[4-8]}$ as an indirect mode of application where the target is exposed to plasma pre-treated solutions. However, the formation of plasma activated liquids as an indirect effect of direct plasma treatment for example within a wound setting can also be considered. A number of recent publications ${ }^{[9-12]}$ have reported on the antimicrobial and cytotoxic activities of PALs such as plasma-activated water or plasma-activated culture media. PALs may demonstrate similar bactericidal and or cytotoxic effects as that of direct plasma exposure but PAL can facilitate flexibility and precision of delivery with potentially gentler treatment conditions as may be demanded with in-vivo conditions. The long term antimicrobial stability of the PALs could provide the advantages of off-site production, storability and flexibility of application over the direct treatment.

The bactericidal effects of PALs are a result of redox-active species (reactive oxygen and nitrogen species, ROS and RNS) which are mainly generated near the gas-liquid interface and transported into the liquid phase. In the gas phase, atmospheric cold plasmas contain charged particles (electrons and ions) and reactive species such as ozone $\left(\mathrm{O}_{3}\right)$, singlet oxygen $\left({ }^{1} \mathrm{O}_{2}\right)$, superoxide radical $\left(\mathrm{O}_{2}^{--}\right)$, hydroxyl radical $(\cdot \mathrm{OH})$, nitric oxide radical $(\cdot \mathrm{NO})$ and nitrogen dioxide radical $\left(\mathrm{NO}_{2}\right)$. The dissolution of gas plasma species into the liquid phase triggers dynamic chemical reactions and forms a series of aqueous reactive species, some of which are short-lived transient reactive species and difficult to detect ${ }^{[13]}$. Whilst the total biological effect associated with plasma activated liquids may result from a diversity of short and longer lived species, it has been well established in the field of plasma medicine that hydrogen peroxide $\left(\mathrm{H}_{2} \mathrm{O}_{2}\right)$ as well as nitrite $\left(\mathrm{NO}_{2}^{-}\right)$and nitrate $\left(\mathrm{NO}_{3}^{-}\right)$are detected as the stable long- 
lived species in PALs which play an important role for biological effects ${ }^{[14]}$. Consequently, it is suggested that quantitative detections of $\mathrm{H}_{2} \mathrm{O}_{2}, \mathrm{NO}_{2}^{-}$and $\mathrm{NO}_{3}^{-}$could represent a basic indicator for plasma source characterization with regard to the biological activity associated with plasma activated liquids.

Available discharge plasma devices to treat liquids are principally divided into two types. One type is direct exposure of liquids to the plasma discharge, in which water is placed in the discharge gap. The other is the indirect treatment of liquids by post-discharge plasma species which is either from plasma jets or natural diffusion of plasma species, such as the surface dielectric barrier discharge (DBD). Shimizu and co-workers visualized the gas density variation in a pulsed streamer discharge above the water surface by Schlieren imaging and measured the concentration of $\mathrm{H}_{2} \mathrm{O}_{2}$ and $\mathrm{HNO}_{2}$ in the water by a water quality meter ${ }^{[15]}$. Sato and co-workers used a similar discharge device to treat cell culture media. They measured $\mathrm{H}_{2} \mathrm{O}_{2}$ concentrations and compared the effects of plasma-treated and $\mathrm{H}_{2} \mathrm{O}_{2}$ supplemented cell culture medium on the growth and viability of HeLa cells, suggesting that $\mathrm{H}_{2} \mathrm{O}_{2}$ is the key inactivation factor for cell viability ${ }^{[16]}$. Machala and co-workers published a series of work on DC power supply driven self-pulsed streamer corona and transient spark discharges and investigated the respective antimicrobial activities. They reported on the chemical and bactericidal effects of transient spark discharge plasma in electro-sprayed water ${ }^{[17]}$. Lukes and coworkers reported evidence for the formation of peroxynitrite through a pseudo-secondorder post-discharge reaction of $\mathrm{H}_{2} \mathrm{O}_{2}$ and $\mathrm{HNO}_{2}$ generated in a pulsed air discharge in contact with water ${ }^{[18]}$. Ercan and co-workers reported comprehensively on the antimicrobial efficacy of solutions treated by dielectric barrier discharge plasma ${ }^{[4]}$ emphasising the acid and hydrogen peroxide effects and their dependence on holding time, delay time and liquid-aging, where they suggest that DBD plasma-activated antimicrobial solutions are broad-spectrum and retain their efficacies for extended periods of up to 2 years. Graves and co-workers 
generated PAL indirectly in a sealed container with the plasma source installed inside the container yielding a surface DBD and a spark-like discharge ${ }^{[19,20]}$. With surface DBD as the plasma source, they measured the concentration of $\mathrm{O}_{3}, \cdot \mathrm{NO}$ and $\mathrm{NO}_{2}$ in the gas phase by FTIR and the concentration of $\mathrm{H}_{2} \mathrm{O}_{2}, \mathrm{NO}_{2}^{-}$and $\mathrm{NO}_{3}^{-}$in the liquid phase for both water and phosphate-buffered saline (PBS) solution reporting the long-term retention the aqueous species and the corresponding antimicrobial activity up to 7 days ${ }^{[21]}$. Thus, liquids activated by both direct and indirect plasma discharge treatment can contain stable $\mathrm{H}_{2} \mathrm{O}_{2}, \mathrm{NO}_{2}^{-}$and $\mathrm{NO}_{3}^{-}$or their mixture dependent on the plasma discharge and liquid conditions. These PALs offer differing composition of reactive species and possess diverse antimicrobial and cytotoxic activities. Thus far, the key parameters to control aqueous species and the corresponding biological activities are plasma discharge time and post storage time of the treated liquid. Dai and co-workers reported on the selective production of reactive species using a nanosecond pulsed discharge in bubbles of different types of gases for liquids ${ }^{[22]}$. $\mathrm{H}_{2} \mathrm{O}_{2}$ was the predominant species produced using Ar plasma, while predominantly $\mathrm{NO}_{2}^{-}$ and $\mathrm{NO}_{3}^{-}$were generated using air plasma. Employing air as the plasma working gas confers many advantages for ease, cost and flexibility of use. Therefore, we present a study on reactive species specificity in water using air. This tailoring of the reactive species has been achieved by means of treating water with simple AC spark and glow discharges to open air. Two types of air discharge in contact with water are performed and the corresponding reactive species inside two kinds of PAW are analyzed and compared in terms of stable species $\mathrm{H}_{2} \mathrm{O}_{2}$, $\mathrm{NO}_{2}^{-}$and $\mathrm{NO}_{3}^{-}$.

\section{Experimental Section}

\subsection{AC High Voltage Discharges above the Deionized Water}


Two types of electrical discharge configurations have been set up. In both setups, a stainlesssteel needle served as the high voltage (HV) electrode and was fixed perpendicular to the water surface. The distance between the HV needle tip and the water surface was fixed to 5 $\mathrm{mm}$ in all experiments. For each treatment of the water sample, $10 \mathrm{ml}$ volume deionized water was accurately added into a plastic petri dish (55 mm inner dimeter) via a pipette, which corresponded to a water layer of about $4.2 \mathrm{~mm}$ depth. To realize two different discharge modes, the ground electrode connection was adjusted in two setups. In Figure 1(a), the plastic petri dish was placed on a stainless-steel plate which was connected to the ground; in Figure 1(b) a thin ground electrode rod was submerged into the DI (deionized) water contained in the petri dish. Both types of discharges were operated in open air.

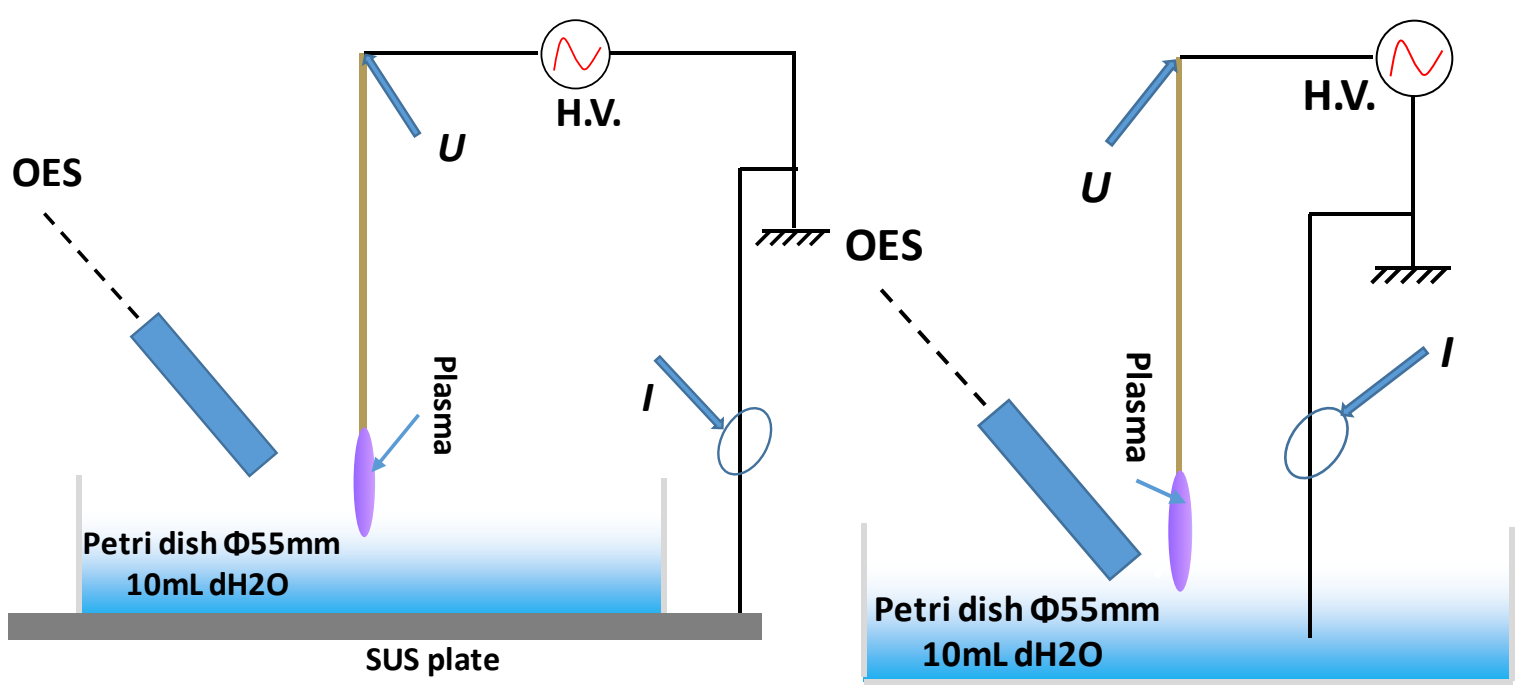

(a)

(b)

Figure 1. Schematic of air discharge in contact with water, (a) spark discharge, (b) glow discharge

The power supply used for driving plasma discharges was a HV half bridge resonant inverter circuit (PVM500, INFORMATION UNLIMITED). Its maximum output voltage was $20 \mathrm{kV}$ with a variable frequency of $20 \mathrm{kHz}$ to $65 \mathrm{kHz}$ depending on the plasma load capacitance. Applied voltage and discharge current were monitored by a Tektronix P6015A HV probe and an ELDITEST CP6990 current probe, respectively. The HV probe and the current probe were 
connected to the high-impedance inputs of an InfiniVision DSO-2014A oscilloscope (Agilent Technologies, 100-MHz bandwidth and 2-G Samples/s sampling rate). The optical emission spectrum of the plasma discharges above the water surface was measured by a CCD spectrometer (Exemplar LS, BWTEK). The light from the plasma discharges was focused by a fiber optic lens and guided to the spectrometer via a multi-mode fiber optic cable. The fiber optic lens mounted on a post was placed at an angle of $45^{\circ}$ with respect to the $\mathrm{HV}$ electrode axis.

\subsection{Measurement of Hydrogen Peroxide, Nitrite and Nitrate Concentrations}

$\mathrm{H}_{2} \mathrm{O}_{2}$ concentrations in PAW were quantified employing the titanium oxysulfate ( $\mathrm{TiOSO}_{4}$, Sigma-Aldrich, product number 89532) colorimetric method. $10 \mu 1 \mathrm{TiOSO}_{4}$ solution was added to $100 \mu 1$ of PAW. After 10 min incubation, absorbance was read on a spectrophotometric plate reader at $405 \mathrm{~nm}$ wavelength. A standard curve of known $\mathrm{H}_{2} \mathrm{O}_{2}$ concentrations was included on each plate and used to convert absorbance into $\mathrm{H}_{2} \mathrm{O}_{2}$ concentration. To prepare $\mathrm{H}_{2} \mathrm{O}_{2}$ calibration curve, $30 \%$ hydrogen peroxide standard solution ((Perhydrol®) for analysis EMSURE® ISO) was diluted into a concentration range of 0 , $2 \times 10-4 \%, 3 \times 10-4 \%, 5 \times 10-4 \%, 1 \times 10-3 \%, 2 \times 10-3 \%, 3 \times 10-3 \%$ and $5 \times 10-3 \%(1 \%=0.3263$ M). Figure 7 (a) is $\mathrm{H}_{2} \mathrm{O}_{2}$ calibration curve. $\mathrm{NO}_{2}^{-}$was measured by Griess reagent (SigmaAldrich, product number 03553 ). $50 \mu 1$ Griess reagent was added to $50 \mu 1$ of PAW. After 30 min incubation, absorbance was read at $548 \mathrm{~nm}$. A range of $\mathrm{NaNO}_{2}$ solutions of known concentrations $(0,40 \mathrm{uM}, 50 \mathrm{uM}, 60 \mathrm{uM}, 80 \mathrm{uM}, 100 \mathrm{uM}, 200 \mathrm{uM}, 300 \mathrm{uM})$ were prepared to make the $\mathrm{NO}_{2}^{-}$calibration curve and used to convert absorbance into $\mathrm{NO}_{2}^{-}$concentrations.

Figure 8 (a) shows $\mathrm{NO}_{2}^{-}$calibration curve. Since the absorbance of $\mathrm{NO}_{2}^{-}$is over range in glow discharge treated water with long treatment. The glow discharge treated water with treatment time longer than 5 minutes were diluted properly before measurement. $\mathrm{NO}_{3}^{-}$concentrations 
were determined photometrically by 2,6-dimethyl phenol (DMP) using the Spectroquant nitrate assay kit (Merck 1.09713, Darmstadt, Germany) and calculated using a $\mathrm{NaNO}_{3}$ standard curve, which comprised a set of standard concentrations of $0,0.1,0.2,0.5,1$, 2, 4 and $5 \mathrm{mM}$. Samples were pretreated with sulfamic acid to eliminate nitrite interference. $\mathrm{NaNO}_{3}$ Figure 9 (a) shows $\mathrm{NO}_{3}^{-}$standard curve. The $\mathrm{pH}$ and conductivity of PAW were measured by an Orion pH meter (model 420A) and conductivity meter (model 150A+), respectively. All measurements of $\mathrm{H}_{2} \mathrm{O}_{2} / \mathrm{NO}_{2}^{-} / \mathrm{NO}_{3}^{-} / \mathrm{pH} /$ conductivity were taken immediately after the plasma treatments. The number of replicate experiments for each measurement of conductivity, $\mathrm{pH}$ value and species concentration is three $(\mathrm{n}=3)$. The error bars show the standard deviation of the measurements.

\section{Results and Discussion}

\subsection{Characteristics of Electrical Discharges above the Deionized Water}

Two types of discharges above the DI water were realized. It can be observed from the voltage and current waveforms in Figures 2 and 3 that the spark discharge was ignited at the positive polarity half period of the applied voltage. Figure 3 shows the waveform in a single discharge pulse. The current comprised a series of oscillating pulses. When the discharge occurred, the current pulse oscillated in a damping mode. The oscillating current pulse lasted for about $250 \mathrm{~ns}$. The amplitude of the current pulse was about $480 \mathrm{~mA}$ after subtraction of the displacement current. The voltage and current waveforms of the AC high voltage driven spark discharge behaves as a transient spark discharge with a high pulse repetition rate of 25 $\mathrm{kHz}$. Glow discharge was ignited at the negative half period of the applied voltage. After the plasma discharge was struck the applied voltage remained constant and resembled a rectangular voltage shape until the next voltage cycle. There was only a small discharge current spike superimposing the displacement. The amplitude of the single discharge pulse in 
each period was about $20 \mathrm{~mA}$ after subtracting the displacement current. This V-I (Voltage Current) characteristic resembles the electrical characteristics of a glow discharge with the water acting as an electrode as reported by Larrousi et al ${ }^{[23,24]}$. However, in the discharge presented here, glow discharge only occurred at the negative polarity half period. The presented glow discharge is similar to a conventional contact glow discharge electrolysis device in which the anode is submerged into the liquid and the cathode is suspended above the liquid surface. The general glow discharge electrolysis device is driven by a DC power supply. Here, the glow discharge was driven by a simple AC power supply. Figure 5 compares the conductivity of the spark and the glow discharge treated waters. The conductivity of the spark discharge treated water increased from the initial level of $1.4 \mu \mathrm{S} / \mathrm{cm}$ to $2.1 \mathrm{mS} / \mathrm{cm}$ after 15 -minutes treatment. While, in glow discharge treated water the conductivity increased slightly to about $310 \mu \mathrm{S} / \mathrm{cm}$ after 15 -minutes treatment.

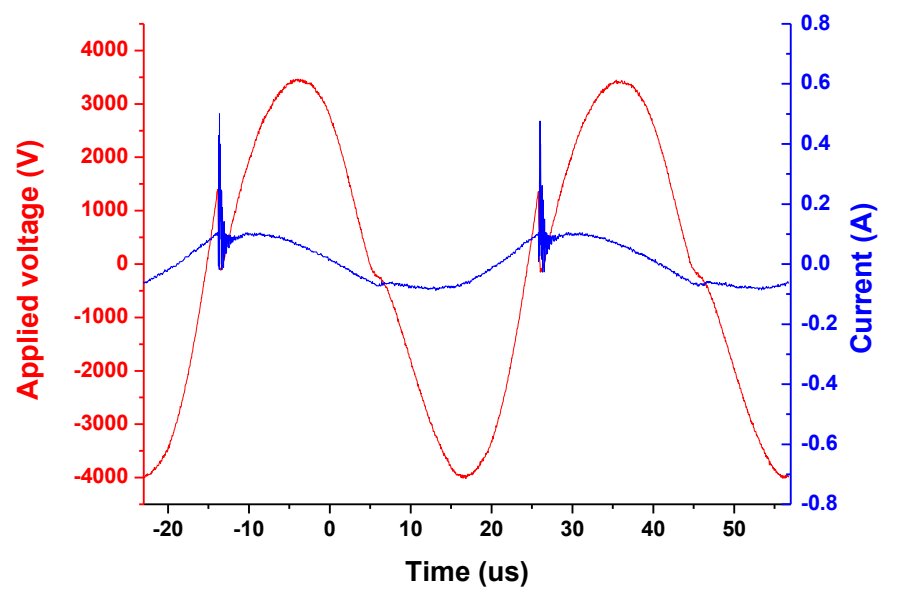

Figure 2. Applied voltage and current waveforms of spark discharge

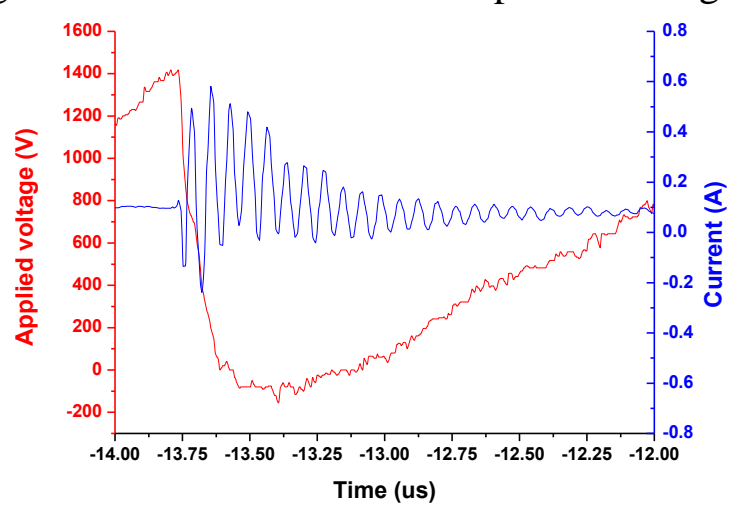

Figure 3. Waveforms for a single discharge pulse in a spark discharge 


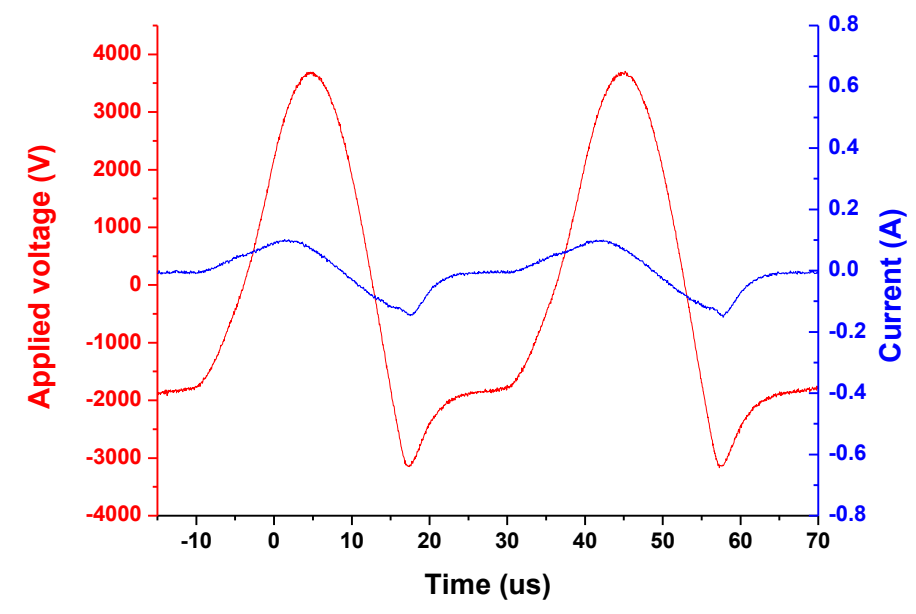

Figure 4. Applied voltage and current waveforms of glow discharge

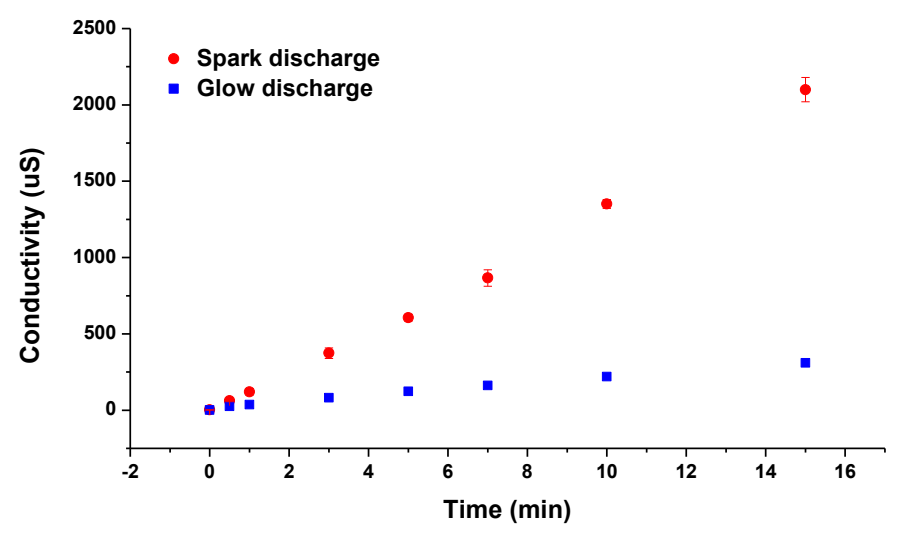

Figure 5. Conductivity of PAW treated by spark and glow discharge plasmas

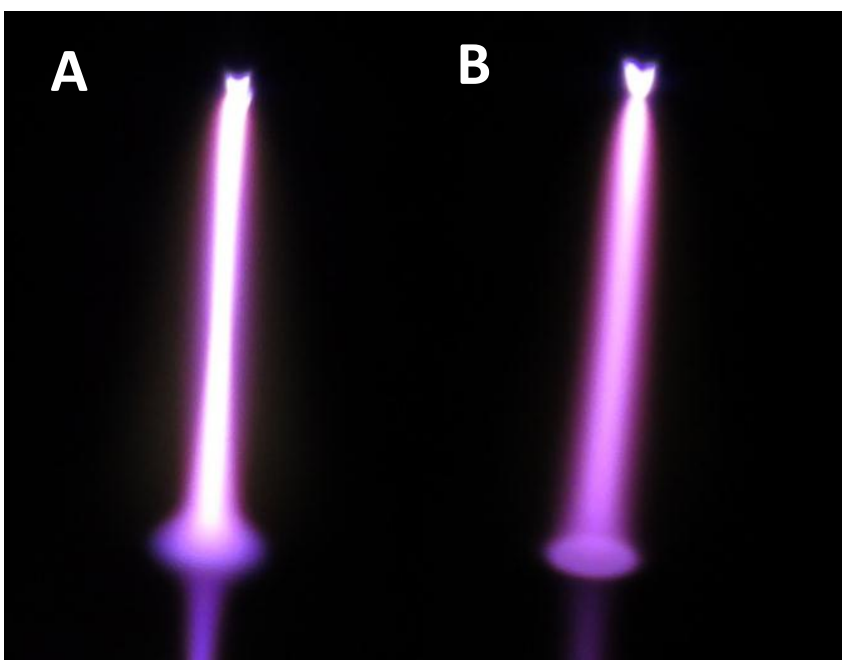

(a) 


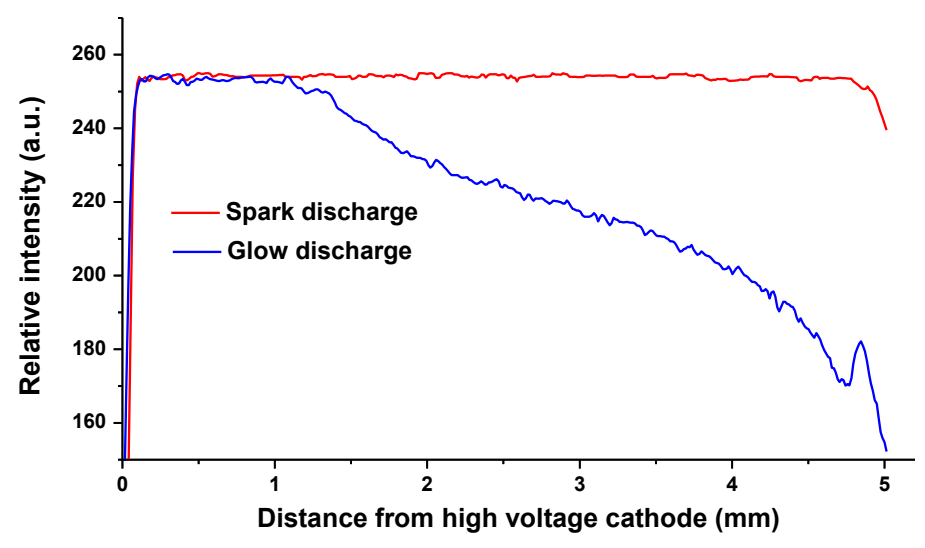

(b)

Figure 6. (a) Images of spark discharge (A) and glow discharge (B) taken by a digital single lens refractive camera Olympus E-620 (Exposure time: 1/10s, ISO: 200), (b) relative optical intensity of spark and glow discharges as a function of distance along axis from high voltage cathode

Photo-A in figure 6 (a) shows a concentrated spark discharge channel, which is similar to a spark phase image of a DC electrical breakdown in a metal pin-water electrode system reported by Bruggeman and coworkers ${ }^{[25]}$. The bright filament fully bridged the gap across the HV electrode and water surface. In comparison, photo-B shows the striation structure of glow discharge, in which the negative glow and the diffusive positive column can be seen. The striation structure is a typical appearance of glow discharges. The discharge's relative intensities corresponding to photo A and B in Figure 6 (a) have been analyzed by the opensource image analysis software ImageJ and plotted as a function of distance from the cathode. Figure 6 (b) clearly shows that in comparison with the constant discharge intensity of spark discharge the intensity of the long positive column in glow discharge gradually decreased and had a small step near anode. Larrousi and Lu has reported the same striation pattern of the AC discharge in contact with water ${ }^{[23,24]}$. It is also noted that the anode pattern in the glow discharge shows a ring-like structure. Bruggeman and coworkers also observed the similar anode pattern in the case of $20 \mathrm{~mA}$ discharge current which was same as our glow discharge current $^{[26]}$. It is noted that the frequencies of the applied voltage for both spark and glow discharges are the same. 


\subsection{Selective Generation of Hydrogen Peroxide, Nitrite and Nitrate}

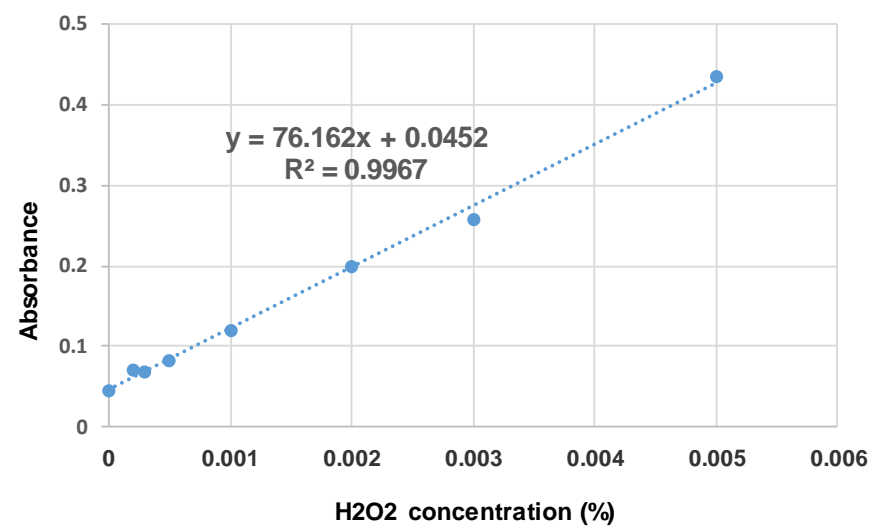

(a)

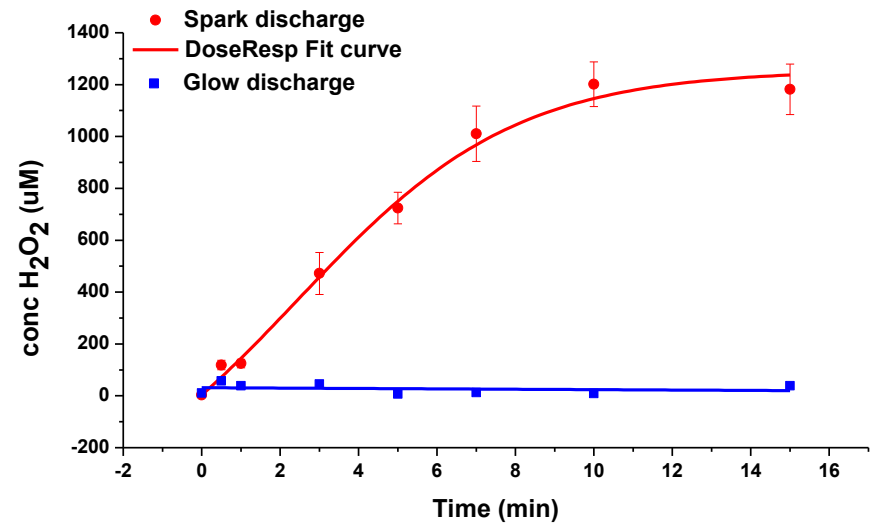

(b)

Figure 7 (a) Standard $\mathrm{H}_{2} \mathrm{O}_{2}$ calibration curve, (b) $\mathrm{H}_{2} \mathrm{O}_{2}$ concentration of PAW treated by spark and glow discharge plasmas

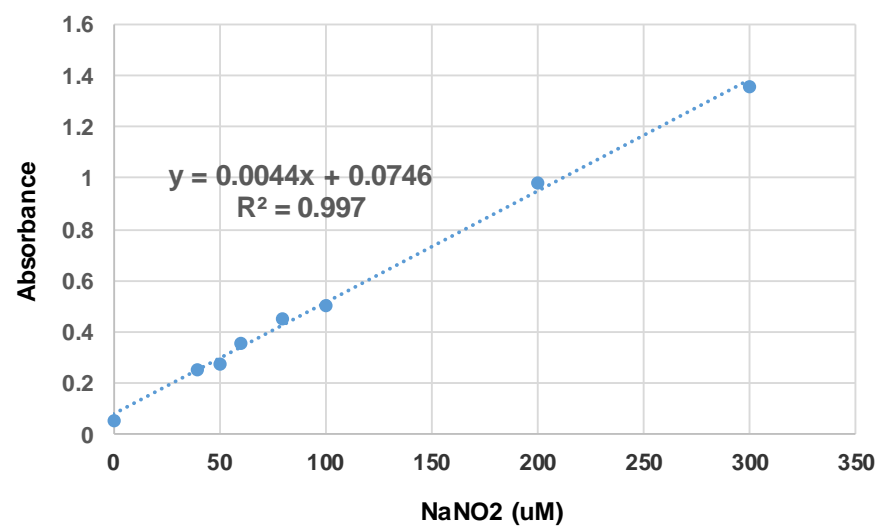

(a) 


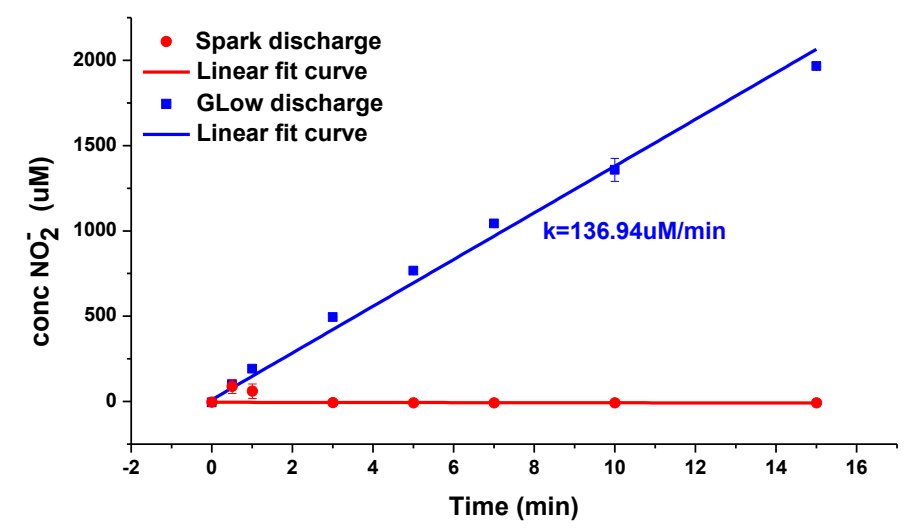

(b)

Figure 8. (a) Standard $\mathrm{NO}_{2}^{-}$calibration curve, (b) $\mathrm{NO}_{2}^{-}$concentration of PAW treated by spark and glow discharge plasmas

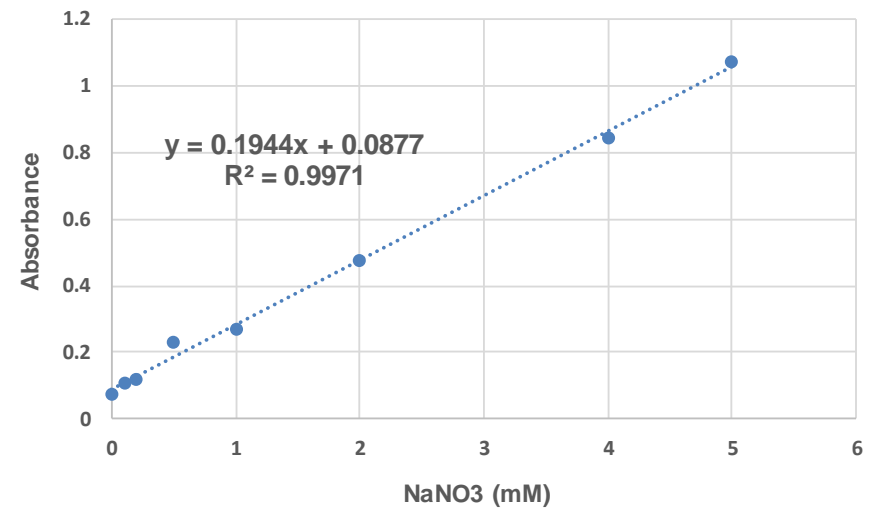

(a)

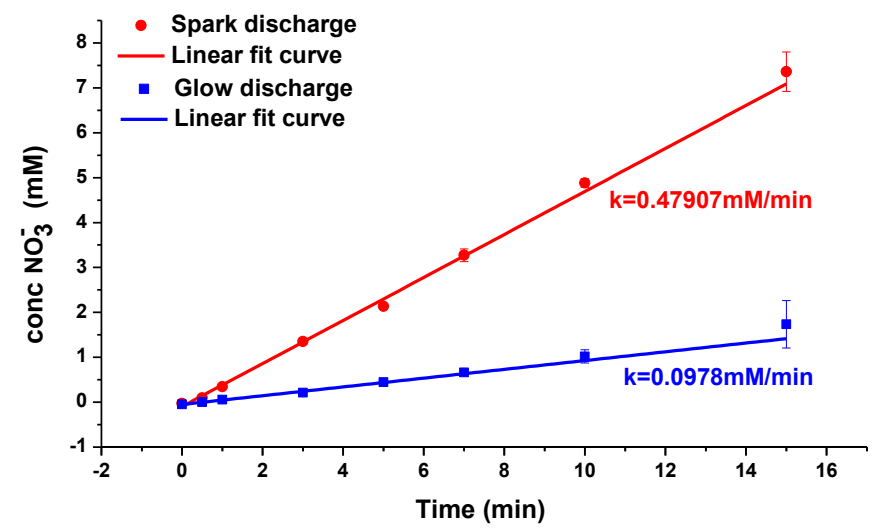

(b)

Figure 9. (a) Standard $\mathrm{NO}_{3}^{-}$calibration curve, (b) $\mathrm{NO}_{3}^{-}$concentration of PAW treated by spark and glow discharge plasmas 
The concentrations of $\mathrm{H}_{2} \mathrm{O}_{2}, \mathrm{NO}_{2}^{-}$and $\mathrm{NO}_{3}^{-}$for both types of PAW were quantitatively measured. The spark discharge PAW (SDPAW) contains $\mathrm{H}_{2} \mathrm{O}_{2}$ and $\mathrm{NO}_{3}^{-}$, while the glow discharge PAW (GDPAW) contains $\mathrm{NO}_{2}^{-}$and $\mathrm{NO}_{3}^{-}$. Figure 7 (b) shows $\mathrm{H}_{2} \mathrm{O}_{2}$ concentration plots of SDPAW and GDPAW. It can be seen that $\mathrm{H}_{2} \mathrm{O}_{2}$ concentration followed the sigmoidal function with the treatment time. $\mathrm{H}_{2} \mathrm{O}_{2}$ concentration increased up to about 1200 $\mu \mathrm{M}$ after 10-minutes treatment, afterwards the concentration plot approached the plateau. In contrast, the amount of $\mathrm{H}_{2} \mathrm{O}_{2}$ in GDPAW showed no increase with treatment time. Figure 8 (b) is the $\mathrm{NO}_{2}^{-}$concentration plots, which show the opposite comparative results with respect to $\mathrm{H}_{2} \mathrm{O}_{2}$ measurement. $\mathrm{NO}_{2}^{-}$concentration of GDPAW linearly increased with treatment time at the slope of $136.94 \mathrm{uM} / \mathrm{min}$ and reached about $1900 \mathrm{uM}$ after 15-minutes treatment; while, there was no increase of $\mathrm{NO}_{2}^{-}$concentration in SDPAW. $\mathrm{NO}_{3}^{-}$in both types of PAW were detected and the concentrations also followed the linear increase modes at different slopes. SDPAW produced $\mathrm{NO}_{3}^{-}$at the rate of about $0.479 \mathrm{mM} / \mathrm{min}$, while $\mathrm{NO}_{3}^{-}$was produced in GDPAW at a lower rate of about $0.0978 \mathrm{mM} / \mathrm{min}$. Total reactive species concentration of SDPAW was higher than the value of GDPAW. In this paper, these stable reactive species were only measured photometrically by chemical probing methods. Aqueous reactive species can be also measured by other methods, such as the UV absorption spectroscopy which has been used to measure reactive species in PAW, for example in Oh and coworkers' work ${ }^{[27]}$. Comparison of the chemical probing methods with other methods in future work would benefit to improve the accuracy of species measurement and to detect another unstable species. It is known that the $\mathrm{pH}$ of plasma activated non-buffer liquids decreases. Figure 10 shows $\mathrm{pH}$ plots for both types of PAW. The initial pH of DI water was about 5.3. The $\mathrm{pH}$ dropped rapidly in the first minute of treatment for both processes. For the spark discharge plasma treated water the $\mathrm{pH}$ subsequently decreased gradually to 2.2 after 10-minutes treatment. 
While for the glow discharge activated water, after an initial decline to about $\mathrm{pH} 3.7$ in the first minute, the $\mathrm{pH}$ level remained constant thereafter.

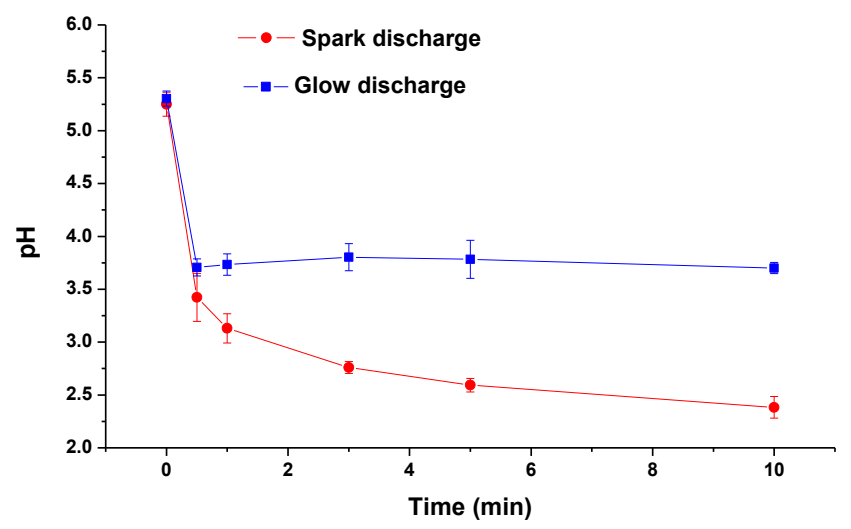

Figure 10. $\mathrm{pH}$ value of PAW treated by spark and glow discharge plasmas

$\mathrm{NO}$ and $\mathrm{NO}_{2}$ are the precursor radicals for the formation of $\mathrm{NO}_{2}^{-}$and $\mathrm{NO}_{3}^{-}$in PAW. Air discharge has been widely employed as $N O_{x}$ generator due to its relatively high temperature of air plasma. In plasma discharges the production of $N O$ mainly follows the Zeldovich mechanism via the reactions of (1) and (2). The formed $\mathrm{NO}$ can be easily oxidized to $\mathrm{NO}_{2}$, via reactions (3) and (4). The generated $\mathrm{NO}$ and $\mathrm{NO}_{2}$ can subsequently dissolve into water, leading to the formation of $\mathrm{NO}_{2}^{-}$- and $\mathrm{NO}_{3}^{-}$(reactions 5 and 6).

$$
\begin{aligned}
& \mathrm{O}+\mathrm{N}_{2} \rightarrow \mathrm{NO}+\mathrm{N} \\
& \mathrm{N}+\mathrm{O}_{2} \rightarrow \mathrm{NO}+\mathrm{O} \\
& \mathrm{O}+\mathrm{NO}+\mathrm{M} \rightarrow \mathrm{NO}_{2}+\mathrm{M}, \mathrm{M}=\mathrm{N}_{2}, \mathrm{O}_{2}, \mathrm{NO}, \mathrm{NO}_{2} \\
& \mathrm{NO}+\mathrm{O}_{3} \rightarrow \mathrm{NO}_{2}+\mathrm{O}_{2} \\
& \mathrm{NO}_{2}+\mathrm{NO}_{2}+\mathrm{H}_{2} \mathrm{O} \rightarrow \mathrm{NO}_{2}^{-}+\mathrm{NO}_{3}^{-}+2 \mathrm{H}^{+} \\
& \mathrm{NO}+\mathrm{NO}_{2}+\mathrm{H}_{2} \mathrm{O} \rightarrow 2 \mathrm{NO}_{2}^{-}+2 \mathrm{H}^{+} \\
& \mathrm{NO}_{2}^{-}+\mathrm{H}_{2} \mathrm{O}_{2}+\mathrm{H}^{+} \rightarrow \mathrm{O}=\mathrm{NOOH}+\mathrm{H}_{2} \mathrm{O} \\
& \mathrm{O}=\mathrm{NOOH} \rightarrow \mathrm{NO}_{3}^{-}+\mathrm{H}^{+} \\
& \mathrm{NO}+\cdot \mathrm{OH} \rightarrow \mathrm{HNO}_{2} \\
& \mathrm{NO}_{2}+\cdot \mathrm{OH} \rightarrow \mathrm{HNO}_{3}
\end{aligned}
$$

Figure 11 shows the optical emission spectra for both discharges which are mainly in the UV region. In both discharges, at the initial stage after discharge ignition the discharge channel 
appears the branching filaments moving erratically from the HV electrode tip. After about 1minute the discharge channel becomes stabilized and localized. OES measurements for both discharges were performed at 2 minutes after discharge ignition. Time-resolved OES measurements with increasing of plasma treatment time have not been performed. However, it can be reasonably suggested that the overall OES intensity could increase with the plasma discharge time since the water conductivity and discharge current increase with time. Major spectral bands between $315 \mathrm{~nm}$ to $405 \mathrm{~nm}$ are attributed to molecular nitrogen second positive system $N_{2}(C-B)$. The bands of $\boldsymbol{O H}(A-X)$ around $295.12 \mathrm{~nm}(3,2)$ and $309.23 \mathrm{~nm}(0,0)$ are also seen. The rotational and vibrational temperatures in the glow discharge were estimated to be around $2500 \mathrm{~K}$ and $3500 \mathrm{~K}$ by the spectral fit at spectral peaks of $337.13 \mathrm{~nm}(0-0), 375.54$ $\mathrm{nm}(1-3)$ and $380.49 \mathrm{~nm}(0-2))$. The glow plasma temperatures are in the similar range (1600$3500 \mathrm{~K})$ as reported in previous studies ${ }^{[24,26,28]}$, which have the similar discharge setups and current conditions as ours. It is known that the constriction of glow discharge phase leads to the formation of spark discharge when the energy dissipated into glow discharge exceeds a critical value. The gas temperature in the concentrated narrow spark channel is higher than the temperature in the glow phase. In the spark discharge the rotational and vibrational temperatures would be in the higher range of $3000-4500 \mathrm{~K}$ and $4000-5000 \mathrm{~K}$, respectively ${ }^{[29}$, ${ }^{30]}$. The higher temperature in the spark discharge favors the formation of $\mathrm{NO}_{2}$ in the gas phase, which results in the higher concentration of $\mathrm{NO}_{3}^{-}$in SDPAW. Pavlovich and coworkers have reported a spark-like air discharge $\mathrm{NO}_{\text {x }}$ generator, in which $\mathrm{NO}_{2}$ concentration is 20 times higher than the value of $\mathrm{NO}$ and the corresponding $\mathrm{NO}_{3}^{-}$in the liquid is much higher than $\mathrm{NO}_{2}^{-[20]}$. The other possible reason why $\mathrm{NO}_{2}^{-}$is not measured in SDPAW is that the mixture of $\mathrm{NO}_{2}^{-}$with $\mathrm{H}_{2} \mathrm{O}_{2}$ under the acid condition generates 
peroxynitrous acid $(\mathrm{O}=\mathrm{NOOH})($ reaction 7), which is unstable and easily decomposes into $\mathrm{NO}_{3}^{-}(\text {reaction } 8)^{[17,31]}$.

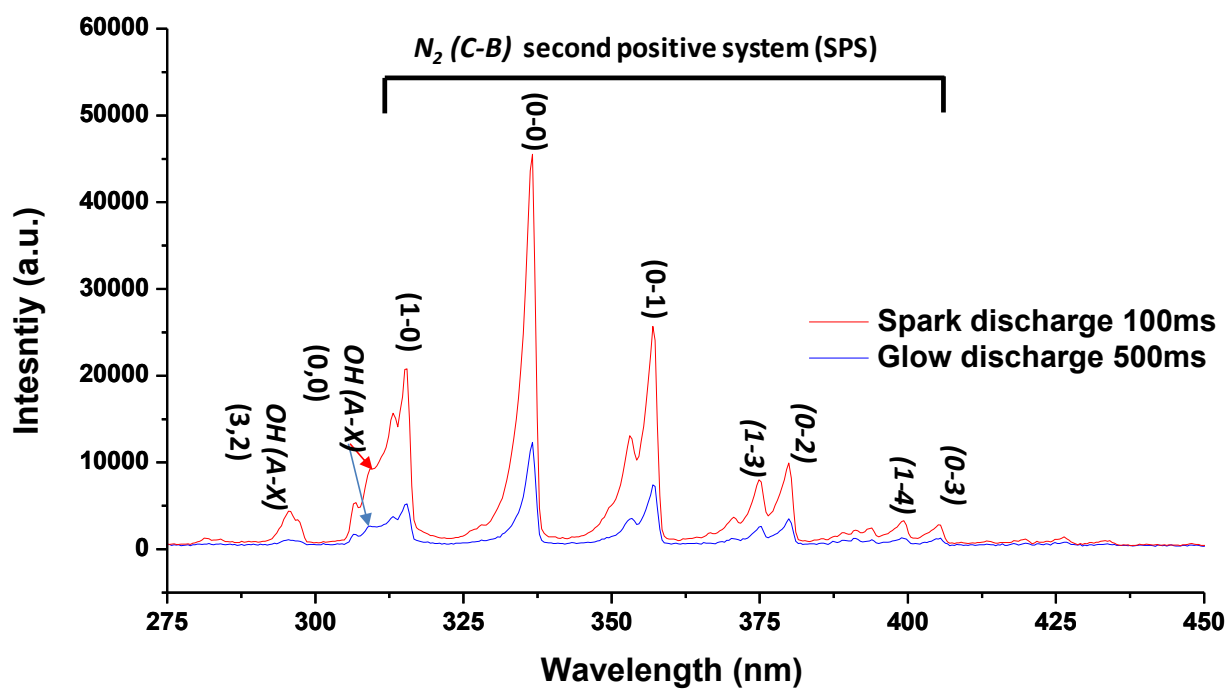

Figure 11. Optical emission spectrum of spark and glow discharges in contact with water

Plasma discharge in contact with water also produces $\cdot \mathrm{OH}$ which is the precursor for the formation of $\mathrm{H}_{2} \mathrm{O}_{2}$ (reaction 17) in liquid phase. It has been widely reported that pulsed DC discharges in contact with water produces $\cdot \mathrm{OH}$ radical in the gas phase. Bruggeman discussed . $\mathrm{OH}$ production in water using atmospheric pressure plasmas ${ }^{[32]}$. In mixtures of air and water molecules $\cdot \mathrm{OH}$ is produced mainly due to the electron induced dissociation (reactions 11 and 12). Moreover, dissociative recombination is also an effective pathway for $\cdot \mathrm{OH}$ production. Electron-ion (reactions 13 and 14) and ion-ion (reactions 15 and 16) recombination reactions have high rates for $\cdot \mathrm{OH}$ production.

The water molecule content in the discharge environment influences the gas phase plasma chemistry, particularly the concentrations of $\mathrm{OH}$ and $\mathrm{H}_{2} \mathrm{O}_{2}$. During discharge the water molecule cluster in the air can be either sputtered into the air by ion bombardment or evaporated by discharge produced thermal heating. Therefore, the water temperature during both types of discharge treatment was measured by a thermometer.

$$
\mathrm{H}_{2} \mathrm{O}+e \rightarrow \cdot \mathrm{H}+\cdot \mathrm{OH}+e
$$




$$
\begin{gathered}
\mathrm{H}_{2} \mathrm{O}+e \rightarrow \cdot \mathrm{H}+\cdot \mathrm{O}+\cdot \mathrm{H}+e \\
\mathrm{H}_{2} \mathrm{O}^{+}+e \rightarrow \cdot \mathrm{H}+\cdot \mathrm{OH} \\
\mathrm{H}_{3} \mathrm{O}^{+}+e \rightarrow \mathrm{H}_{2}+\cdot \mathrm{OH}+e \\
\mathrm{H}_{2} \mathrm{O}^{+}+\mathrm{H}^{-} \rightarrow \mathrm{H}_{2}+\cdot \mathrm{OH} \\
\mathrm{H}_{3} \mathrm{O}^{+}+\mathrm{H}^{-} \rightarrow \mathrm{H}_{2}+\cdot \mathrm{OH}+\cdot \mathrm{H} \\
\cdot \mathrm{OH}+\cdot \mathrm{OH} \rightarrow \mathrm{H}_{2} \mathrm{O}_{2}
\end{gathered}
$$

The water surface temperature rose to about $43^{\circ} \mathrm{C}$ from initial $21^{\circ} \mathrm{C}$ after 3 minutes in both discharges. In spark discharge, water is the cathode. Ions impinging onto the water surface lead to the sputtering of water molecules. Electron dissociation of water molecules leads to the formation of $\mathrm{OH}$ which further forms $\mathrm{H}_{2} \mathrm{O}_{2}$ in both air and water. While, in the glow discharge the high voltage electrode is the cathode, the electrons reaching the water surface dissolute into water. Only small amounts of $\cdot \mathrm{OH}$ might be generated close to the water surface which react with nitrogen oxides (reaction 9 and 10), forming $\mathrm{NO}_{2}^{-}$and $\mathrm{NO}_{3}^{-}$. To study the influence of moisture above the water surface on the generation of $\mathrm{H}_{2} \mathrm{O}_{2}$, both types of discharges were operated in a closed glass vial which was preheated to generate extra water vapor. Figure 12 shows the comparison of $\mathrm{H}_{2} \mathrm{O}_{2}$ concentration of the SDPAW and GDPAW with and without additional water vapor in the glass vial. In the case of SDPAW, $\mathrm{H}_{2} \mathrm{O}_{2}$ concentration was increased significantly in the preheated vial. However, when the preheated vial was employed with GDPAW, the $\mathrm{H}_{2} \mathrm{O}_{2}$ concentration still showed no change. It is noted that there is a discrepancy in $\mathrm{H}_{2} \mathrm{O}_{2}$ concentration between Figures 7 and 12 (without additional water vapor). The discrepancy is due to the different capacitive load characteristics of plasma discharges above the water surfaces. $10 \mathrm{~mL}$ water columns contained in the petri dish and glass vial have the different water capacitance. In addition, the bottom plate capacitances of petri discharge and glass vial are also different. Hence, the total equivalent capacitances are different between two setups (for Figure 7 and Figure 12). In this study, the discharge is tuned by a HV half bridge resonant inverter circuit and the discharge is 
ignited near the resonance point. Therefore, for a given discharge setup the resonance frequency is different, and the displacement current and discharge current are different.

Consequently, the concentrations of $\mathrm{H}_{2} \mathrm{O}_{2}$ inside PAW are different between Figure 7 and 12 . Nevertheless, the objective of Figure 12 is to show the influence of moisture on the generation of $\mathrm{H}_{2} \mathrm{O}_{2}$ for both types of discharges.

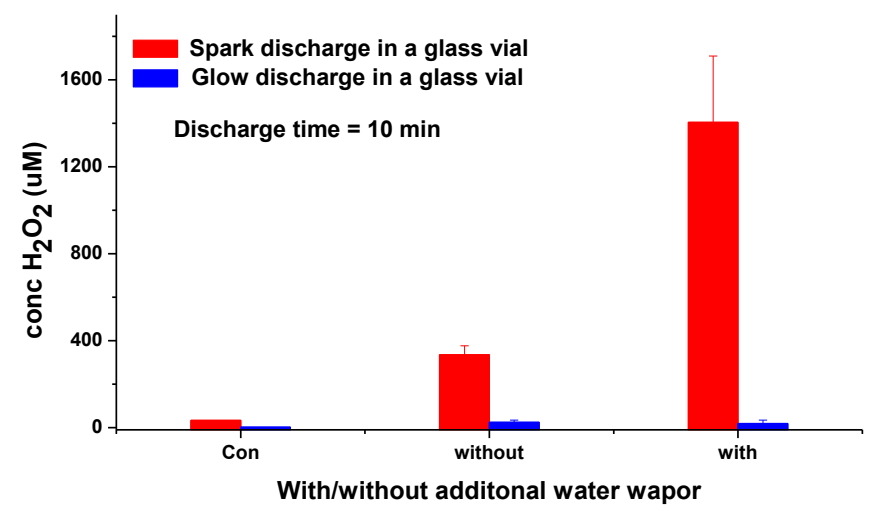

Figure 12. $\mathrm{H}_{2} \mathrm{O}_{2}$ concentration of PAW treated by spark and glow discharge with and without additional water vapor ("con" =untreated by discharge, "without" and "with" =without and with additional water vapor)

The presented glow discharge is essentially a contact glow discharge electrolysis, which includes both processes of glow discharge in the air and electrolysis in the water. During the discharge, $\mathrm{H}_{2} \mathrm{O}_{2}$ formed in the water is simultaneously electrolyzed into oxygen and water (reaction 18). Therefore, only $\mathrm{NO}_{2}^{-}$has been measured, while no $\mathrm{H}_{2} \mathrm{O}_{2}$ was detected. To observe the clear bubbles around the anode, glow discharge was performed in a glass vial. Oxygen bubbles around the anode rod in the water (reaction 19) can be clearly seen during discharge as shown in Figure 13. To understand the effect of the anode area on $\mathrm{H}_{2} \mathrm{O}_{2}$ electrolytic decomposition, the anode rod was replaced by a mesh anode in the water. In the case of the mesh anode, the amount of oxygen bubbles generated during the discharge was significantly increased (data not shown), which also confirms the electrolysis effect of $\mathrm{H}_{2} \mathrm{O}_{2}$. 


$$
\begin{array}{r}
2 \mathrm{H}_{2} \mathrm{O}_{2} \rightarrow 2 \mathrm{H}_{2} \mathrm{O}+\mathrm{O}_{2} \\
4 \mathrm{OH}^{-}+e \rightarrow \mathrm{O}_{2}+2 \mathrm{H}_{2} \mathrm{O}+4 e^{-}
\end{array}
$$

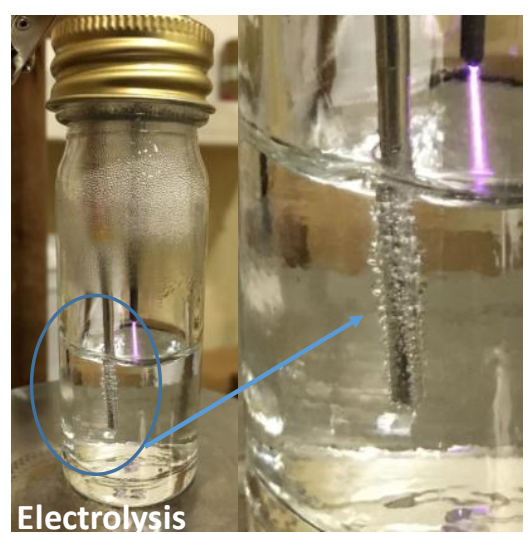

Figure 13. Oxygen bubbles around the anode rode during glow discharge

\section{Conclusion}

We have reported comparative studies on the generation of reactive species in the DI water exposure to open air AC spark and glow discharge plasmas. Spark discharge occurred in the pulse mode at the positive half cycle of a $25 \mathrm{kHz}$ AC high voltage output and the glow discharge was ignited at the negative half period. The corresponding reactive species inside two kinds of PAW are compared in terms of $\mathrm{H}_{2} \mathrm{O}_{2}, \mathrm{NO}_{2}^{-}$and $\mathrm{NO}_{3}^{-}$. SDPAW contains $\mathrm{H}_{2} \mathrm{O}_{2}$ and $\mathrm{NO}_{3}^{-}$, while GDPAW contains $\mathrm{NO}_{2}^{-}$and $\mathrm{NO}_{3}^{-}$. Total reactive species concentration in SDPAW is higher than the value of GDPAW. The higher $\mathrm{NO}_{3}^{-}$concentration in SDPAW is possibly due to its higher plasma temperature, which favors the formation of $\mathrm{NO}_{2}$ in the gas phase with higher densities. In terms of $\mathrm{H}_{2} \mathrm{O}_{2}$ and $\mathrm{NO}_{2}^{-}$, SDPAW is $\mathrm{H}_{2} \mathrm{O}_{2}$ rich, with no $\mathrm{NO}_{2}^{-}$measurable. In contrast, $\mathrm{NO}_{2}^{-}$was measured for GDPAW, while no $\mathrm{H}_{2} \mathrm{O}_{2}$ was detected. The resulting reactive species specificity between two types of PAW is attributable to the different gas phase discharge mechanisms and liquid phase chemical processes. For SDPAW, the humidity above the water surface influences the concentration of $\mathrm{H}_{2} \mathrm{O}_{2}$. On the other hand, for GDPAW the process includes the glow discharge in the gas phase and the electrolysis in 
the liquid phase. Consequently, during discharge $\mathrm{H}_{2} \mathrm{O}_{2}$ formed in the water is electrolyzed into oxygen. The generation and decomposition of peroxynitrous acid $(\mathrm{O}=\mathrm{NOOH})$ in SDPAW are another likely pathway for the consumption of $\mathrm{NO}_{2}^{-}$.

The tailored reactive species specificity produced here using water and air, can serve as a platform to enhance mechanistic understanding of cellular and target interactions with species specific PAL. The selective generation of species using water and air will also facilitate targeted applications of cold plasma activated liquids to various fields including food processing, plasma agriculture, antimicrobial development and cancer therapies, where the roles of different key reactive species is emerging. The tailored specificity reported here can also provide richer parametric spaces for PAL products by combining different discharge modes or mixing different types of PALs.

Acknowledgements: ((Financial contributions to this study were obtained through funding from Science Foundation Ireland, Grant No 14/IA/2626. Peng LU is supported in part by the China Tianjin Research Program of Fundamental and Applied Technology, Grant No 14JCYBJC43000))

Received: ((will be filled in by the editorial staff)); Revised: ((will be filled in by the editorial staff)); Published online: ((please add journal code and manuscript number, e.g., DOI: 10.1002/ppap.201100001))

Keywords: electrolysis; glow discharge; reactive species; plasma activated water; spark discharge 
[1] J. Ehlbeck, U. Schnabel, M. Polak, J. Winter, T. V. Woedtke, R. Brandenburg, T. V. Hagen, K.D. Weltmann, J. Phys. D: Appl. Phys. 2011, 44, 013002.

[2] A Fridman, G. Friedman, Plasma Medicine, Wiley, Hoboken, NJ, USA 2013.

[3] A. Kramer, S. Bekeschus, R. Matthes, C. Bender, M. B. Stope, M. Napp, O.

Lademann, J. Lademann, K. D. Weltmann, F. Schauer, Plasma Process. Polym. 2015, 12, 1410.

[4] U. K. Ercan, H. Wang, H. Ji, G. Fridman, A. D. Brooks, S. G. Joshi, Plasma Process. Polym. 2013, 10, 544.

[5] U. K. Ercan, S. S. Joshi, A. Yost, N. Gogotsi, S. O’Toole, M. Paff, E. Melchior, S. G. Joshi, Advances in Microbiology. 2014, 4, 1188.

[6] M. Naïtali, G. K. Youbi, J. M. Herry, M. N. Bellon-Fontaine, J. L. Brisset, Appl. Environ. Microbiol. 2010, 76, 7662.

[7] Q. Zhang, Y. Liang, H. Feng, R. Ma, Y. Tian, J. Zhang, J. Fang, Appl. Phys. Lett. 2013, 102, 203701.

[8] Hiromasa Tanaka, Masaaki Mizuno, Kenji Ishikawa Kae Nakamura, Hiroaki Kajiyama, Hiroyuki Kano, Fumitaka Kikkawa, Masaru Hori, Plasma Medicine 2011, 1.

[9] U. Schnabel, D. Sydow, O. Schlüter, M. Andrasch, J. Ehlbeck, Modern Agricultural Science and Technology. 2015, 1, 29.

[10] F. Judée, C. Fongia, B. Ducommun, M. Yousf, V. Lobjois, N. Merbahi, Scientific Reports 2016, 6, 21421.

[11] D. Boehm, C. Heslin, P. J. Cullen, P. Bourke, Scientific Reports 2016, 6, 21464.

[12] D. Yan, N. Nourmohammadi, K. Bian, F. Murad, J. H. Sherman, M. Keidar, Scientific Reports 2016, 6, 26016.

[13] D. B. Graves, J. Phys. D: Appl. Phys. 2012, 45, 263001.

[14] H. Jablonowski, T.V. Woedtke, Clinical Plasma Medicine. 2015, 3, 42. 
[15] T. Shimizu, Y. Iwafuchi, G. E. Morfilll, T. Sato, New Journal of Physics 2011, 13, 053025.

[16] T. Sato, M. Yokoyama, K. Johkura, J. Phys. D: Appl. Phys. 2011, 44, 372001.

[17] Z. Machala, B. Tarabova, K. Hensel, E. Spetlikova, L. Sikurova, P. Lukes, Plasma Process. Polym. 2013, 10, 649.

[18] P. Lukes, E. Dolezalova, I. Sisrova, M. Clupek, Plasma Sources Sci. Technol. 2014, $23,015019$.

[19] M. J. Pavlovich, D. S. Clark, D. B. Graves, Plasma Sources Sci. Technol. 2014, 23, 065036.

[20] M. J. Pavlovich, T. Ono, C. Galleher, B. Curtis, D. S. Clark, Z. Machala, D. B. Graves, J. Phys. D: Appl. Phys. 2014, 47, 505202.

[21] M. J. Traylor, M. J. Pavlovich, S. Karim, P. Hait, Y. Sakiyama, D. S. Clark, D. B. Graves, J. Phys. D: Appl. Phys. 2011, 44, 472001.

[22] X. J. Dai, C. S. Corr, S. B. Ponraj, M. Maniruzzaman, A. T. Ambujakshan, Z. Chen, L. Kviz, R. Lovett, G. D. Rajmohan, D. R. de Celis, M. L. Wright, P. R. Lamb, Y. E. Krasik, D. B. Graves, W. G. Graham, R. d'Agostino, X. Wang, Plasma Process. Polym. 2016, 13, 306.

[23] X. Lu, M. Laroussi, IEEE Trans. Plasma Sci. 2005, 33, 27.

[24] X. Lu, M. Laroussi, J. Phys. D: Appl. Phys. 2003, 36, 661.

[25] P. Bruggeman, J. V. Slycken, J. Degroote, J. Vierendeels, P. Verleysen, C. Leys, IEEE Trans. Plasma Sci. 2008, 36, 1138.

[26] P. Bruggeman, J. Liu, A. Maslani, J. Degroote, M. G. Kong, J. Vierendeels, C. Leys, J. Phys. D: Appl. Phys. 2008, 41, 212501.

[27] J. S. Oh, E. J. Szili, N. Gaur, S. H. Hong, H. Furuta, H. Kurita, A. Mizuno, A. Hatta, R. D. Short, J. Phys. D: Appl. Phys. 2016, 49, 304005.

[28] V. A. Titov, V. V. Rybkin, S. A. Smirnov, A. L. Kulentsan, H.-S. Choi, Plasma Chem. Plasma Process. 2006, 26, 543. 
[29] P. Mezei, T. Cserfalvi, L. Csillag, J. Phys. D: Appl. Phys. 2005, 38, 2804.

[30] G. Faure, S.M. Shkol'nik, J. Phys. D: Appl. Phys. 1998, 31, 1212.

[31] D. Gupta, B. Harish, R. Kissner, W.H. Koppenol, Dalton Trans. 2009, 5730.

[32] P. Bruggeman, D. C Schram, Plasma Sources Sci. Technol. 2010, 19, 045025. 


\section{Graphical Abstract}

The table of contents entry should be fifty to sixty words long (max. 400 characters), and the first phrase should be bold. The entry should be written in the present tense and impersonal style. The text should be different from the abstract text.

We present a study on tailoring aqueous reactive species for plasma activated water (PAW) by treating deionized water with air spark and glow discharges in contact with water. Spark discharge PAW contains $\mathrm{H}_{2} \mathrm{O}_{2}$ and $\mathrm{NO}_{3}^{-}$, while $\mathrm{NO}_{2}^{-}$and $\mathrm{NO}_{3}^{-}$are generated in glow discharge PAW. Species specificity can provide richer parametric spaces for producing PALs with controlled impact and dosage achievable.

Peng LU, Daniela Boehm, Paula Bourke*, P J Cullen.

Title: Achieving reactive species specificity within plasma activated water through selective generation using air spark and glow discharges

ToC Figure

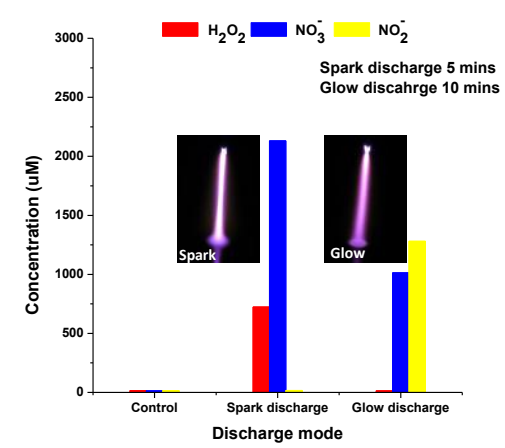

